\title{
Comparative Evaluation of the Effect of Three Different Types of Pattern Materials on the Vertical Marginal Accuracy of Complete Cast Crown: An In Vitro Study
}

\author{
Preetica Sharma ${ }^{1}$ Tarun Kalra ${ }^{1}$ Manjit Kumar ${ }^{1} \quad$ Ajay Bansal ${ }^{1} \quad$ Shefali Singh Malik ${ }^{1}$ \\ ${ }^{1}$ Department of Prosthodontics, Bhojia Dental College and Hospital, \\ Baddi, Himachal Pradesh, India \\ Address for correspondence Manjit Kumar, MDS, Department of \\ Prosthodontics, Bhojia Dental College and Hospital Baddi, 173205, \\ Himachal Pradesh, India (e-mail: manjitkiran@yahoo.co.in).
} Dent J Adv Stud 2022;10:25-31.

\begin{abstract}
Keywords

- casting

- marginal discrepancy

- pattern materials

Aim and Objectives The main aim of this study was to evaluate the effect of three different types of pattern materials on the vertical marginal accuracy of complete cast crown.

Material and Methods Three groups of 20 specimens each were made based on three pattern materials, that is, blue inlay wax, autopolymerizing acrylic resin, and light cure pattern resin. Castings were made and examined using stereo microscope for vertical marginal discrepancy.

Results The result showed that the highest mean gap was noticed in the castings fabricated using inlay type B pattern wax followed by the castings fabricated using autopolymerizing resin and the least mean gap was observed in the castings fabricated using light cure modeling material.

Conclusion It was concluded from this study that the use of light cure modeling material to make patterns for casting with lost wax technique is best recommended than inlay type B pattern and autopolymerizing resin.
\end{abstract}

\section{Introduction}

The prime goal of any prosthodontic treatment is to provide the patient with precisely fitting restoration or prosthesis. ${ }^{1}$ There is no regenerative power in teeth as found in other tissues. Therefore, once enamel or dentin is lost as a result of caries, trauma, or wear, only restorative materials can reestablish form and function. The restoration can survive in the biological environment of the oral cavity only if the margins are closely adapted to the cavosurface finish line of the preparation. The preparation of finish line dictates the shape and bulk of restorative material in the margin of the restoration. ${ }^{2}$ It also can affect both marginal adaptation and the degree of seating of the restoration. Incomplete marginal adaptation has been associated with the development of secondary caries and gingival inflammation. ${ }^{3}$ A cast restoration must seat accurately on the tooth, exhibit a minimum cement margin, be adequately retained, and restore or improve function and aesthetics. Marginal adaptation is considered to be a primary and significant factor in the prevention of secondary caries and is an important indicator of the published online November 22, 2021
DOI https://doi.org/ 10.1055/s-0041-1739506. ISSN 2321-1482.
(C) 2021. Bhojia Dental College and Hospital affiliated to Himachal Pradesh University. All rights reserved.

This is an open access article published by Thieme under the terms of the Creative Commons Attribution-NonDerivative-NonCommercial-License, permitting copying and reproduction so long as the original work is given appropriate credit. Contents may not be used for commercial purposes, or adapted, remixed, transformed or built upon. (https://creativecommons.org/ licenses/by-nc-nd/4.0/)

Thieme Medical and Scientific Publishers Pvt. Ltd., A-12, 2nd Floor, Sector 2, Noida-201301 UP, India 
overall acceptability of the cast restoration. Different materials and different techniques have been used. Therefore, this study was performed to compare the vertical marginal accuracy for complete cast crown made by commercially available inlay wax, autopolymerized pattern resin, and light polymerized pattern resin materials.

\section{Aim and Objective}

The study was performed to compare the vertical marginal accuracy for the complete cast crown made by using inlay type $B$ pattern wax, autopolymerizing resin, and light cure modelling material.

\section{Materials and Methods}

The following materials were used for fabricating the stone dies:

Autopolymerizing resin (DPI, Mumbai), modelling wax (Rolex, Delhi), addition silicone impression material (Coltene, Switzerland), and type IV Die stone (Kalabhai Ultrarock, India) (-Fig. 1).

Materials used for fabrication of patterns:

Inlay type B pattern wax (Bego, Germany), autopolymerized pattern resin (GC Corporation, Japan)
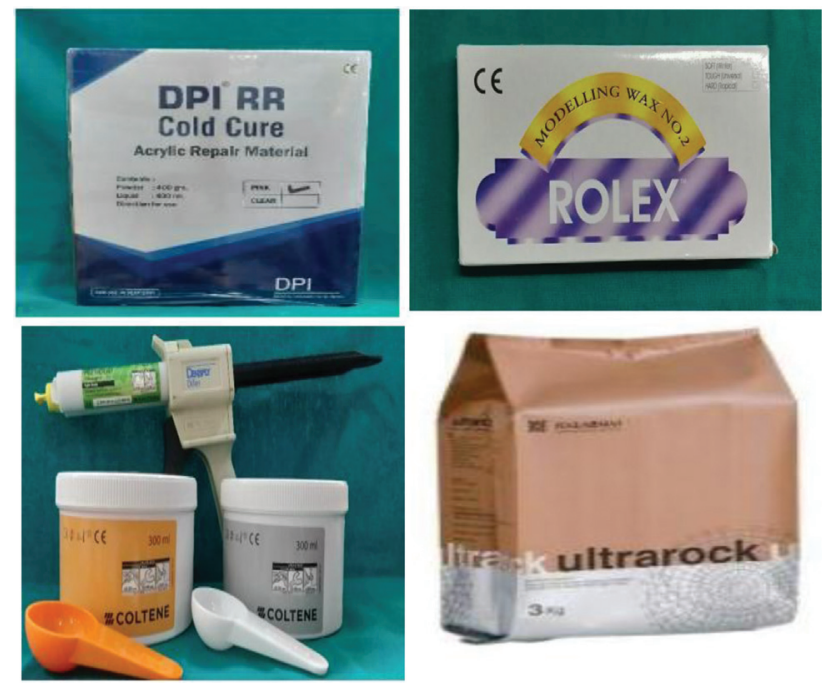

Fig 1 Materials used for die preparation.

Light-curing modeling material (Liwa, Germany), petroleum jelly (Vaseline, India).

Die spacer (Maarc, India) (-Fig. 2).

Materials used for investing and casting:

Phosphate bonded investment material (DFS-DIAMON, Germany), Cobalt -Chromium alloy (Premier Dent International, EU) (-Fig. 3 ).

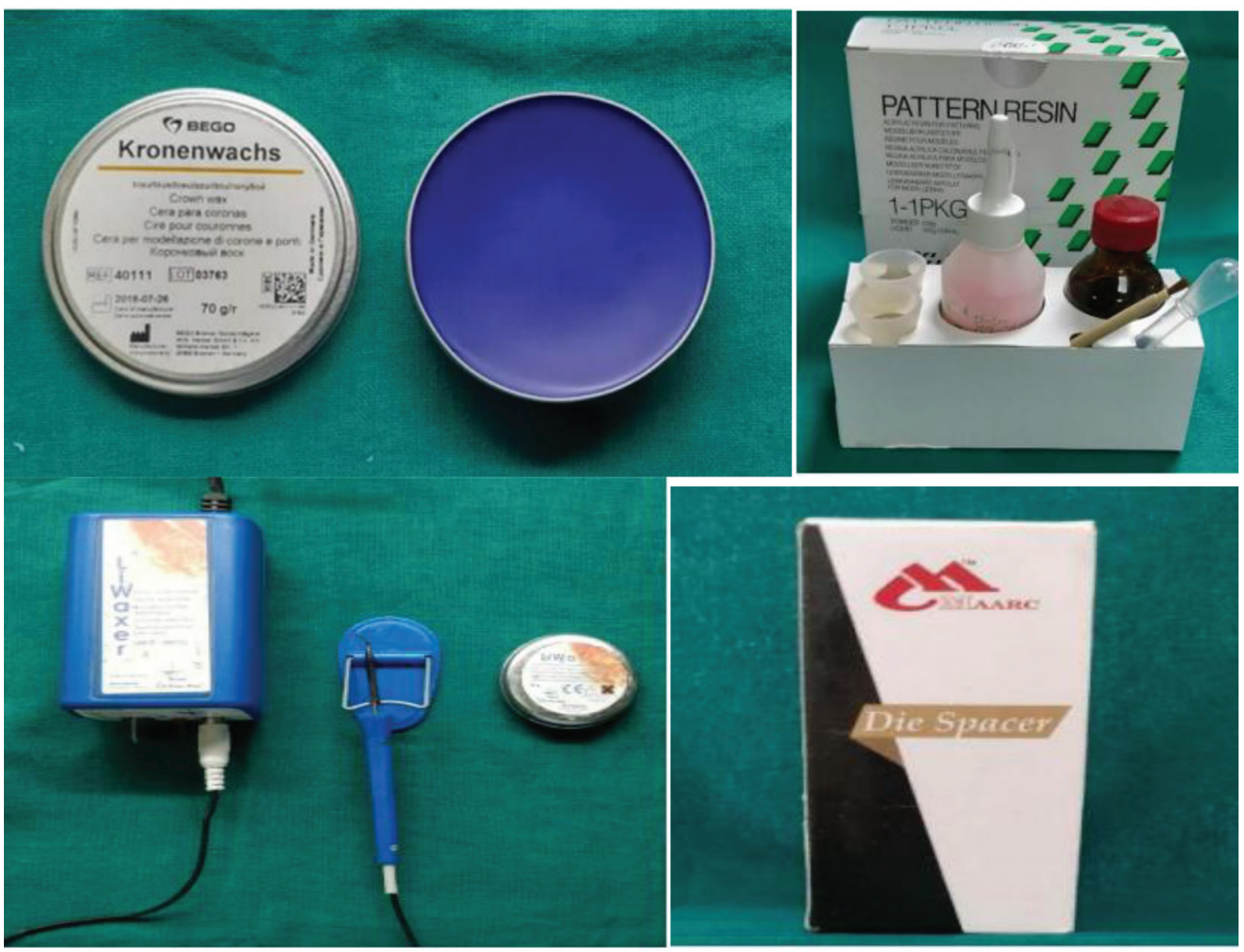

Fig 2 Materials used for fabrication of wax patterns. 


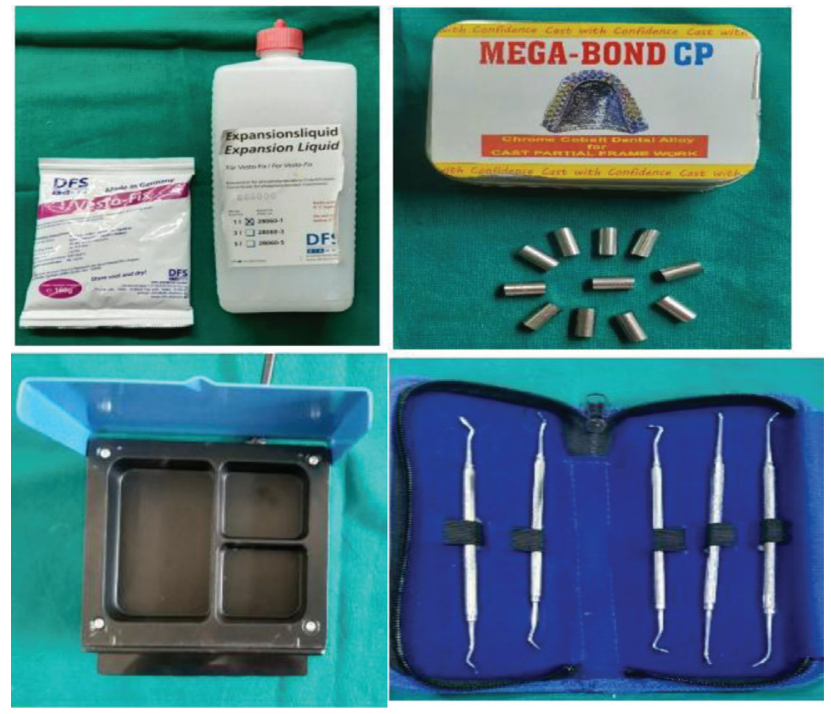

Fig 3 Materials used for investing and casting.

\section{Equipment}

1. Equipment used for fabricating wax patterns:

Wax heater and carver (Seedent, China), PKT instruments (API, India), light-curing unit (Liwa, Germany).

2. Equipment used for investing and casting: Vacuum mixing machine (Austenal, Germany), Burnout furnace (Unident, India), Induction casting machine (Bego, Germany) (-Fig. 4).

3. Equipment used for testing: Stereo microscope (Nikon, Japan) (-Fig. 5).

\section{Methodology}

A standardized metal master die was fabricated simulating a prepared crown (-Fig. 6).

Three groups of 20 specimens each were made based on three pattern materials, that is, blue inlay wax, autopolymerizing acrylic resin, and light cure pattern resin. Castings
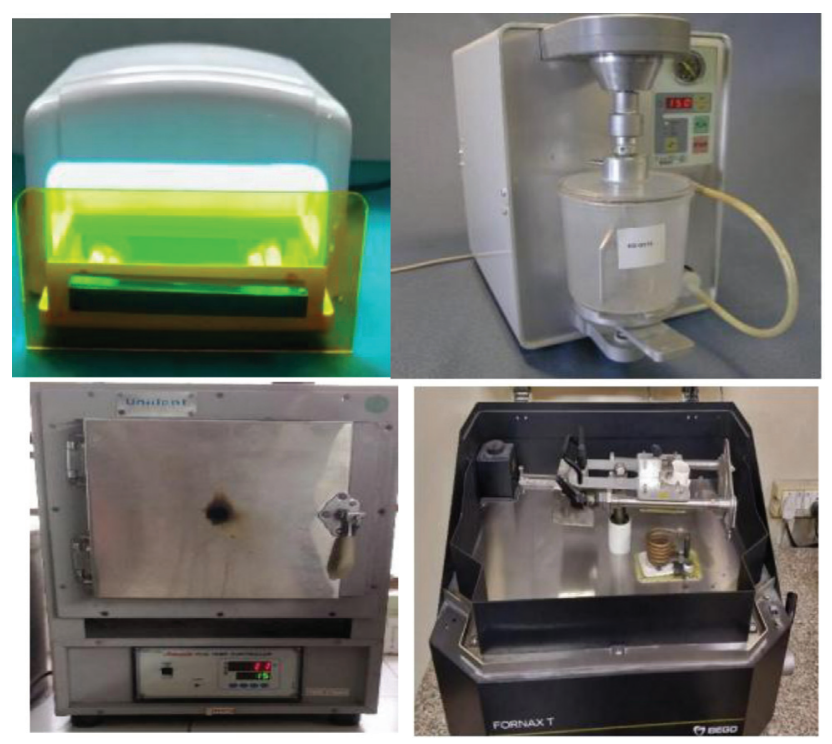

Fig 4 Equipment used for investing and casting and testing samples.

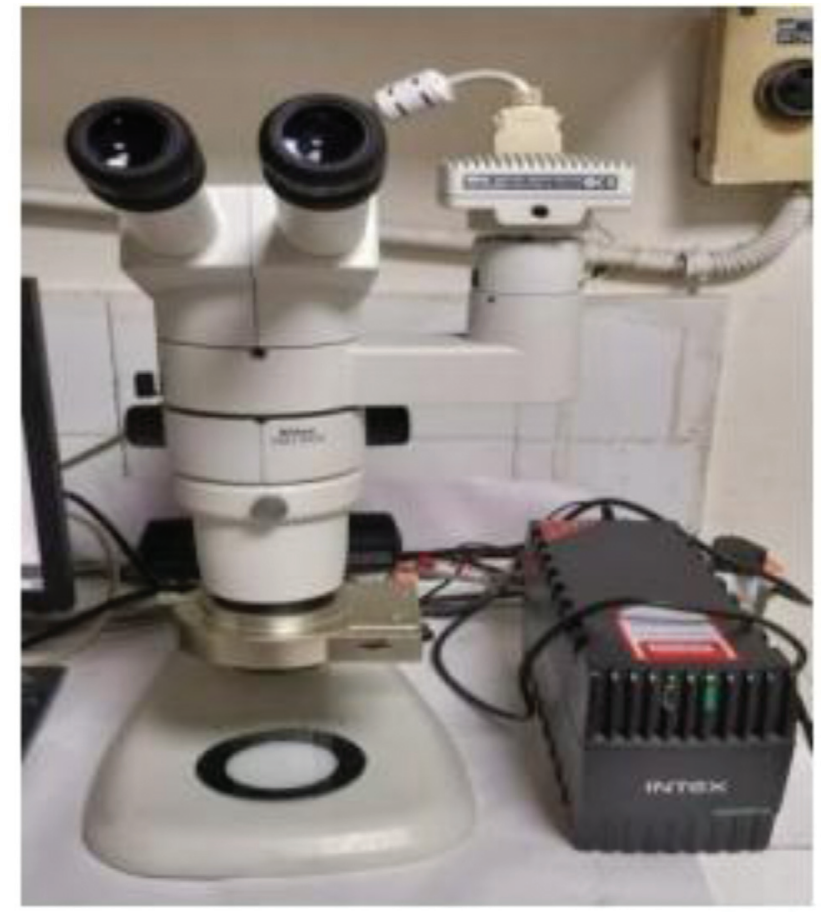

Fig 5 Stereo microscope.

were made and examined using stereo microscope for vertical marginal discrepancy.

Group 1 consisted of 20 individual dies on which pattern was prepared using inlay type B wax pattern.

Group 2 consisted of 20 individual dies on which pattern was prepared using autopolymerizing resin wax pattern. Group 3 consisted of 20 individual dies on which pattern was prepared using light cure modelling material.

\section{Preparation of the Stainless-Steel Master Metal Die}

A stainless-steel master die simulating a prepared crown was fabricated similar in volumetric size to an average molar, that is, cervical diameter of $8 \mathrm{~mm}$ at finish line and height of $5.5 \mathrm{~mm}$ from occlusal surface to the end of preparation, taper of 6 degrees, finish line width $0.8 \mathrm{~mm}$. The occlusal surface was kept flat. A stainless-steel counter sleeve with $1 \mathrm{~mm}$ gap was prepared to standardize the dimension of wax pattern.

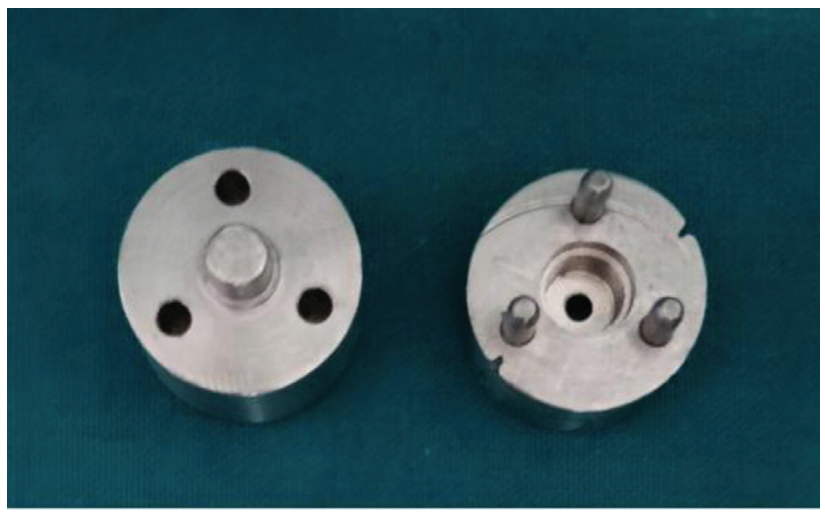

Fig 6 Master die. 
Fabrication of Custom Tray and Impression Making

Two layers of modeling wax adapted to the inner side of the custom tray made with autopolymerizing acrylic resin and impression of the metallic die were made using addition silicon impression material by single step technique.

\section{Duplicate Die Preparation}

After the impression material got set, metallic die was removed. This impression was poured with type IV die stone with water-powder ratio of $25 \mathrm{cc} / 100 \mathrm{~g}$ (as per manufacturer's specification) mechanically mixed using vacuum mixer. After final set, dies were removed from impression. Die hardener (DFS, Germany) was applied to die with the help of brush.

\section{Application of Die Spacer}

The die spacer was applied in an even coating to axial surface within $0.5 \mathrm{~mm}$ above margin. Each coat was allowed to dry before fabrication of wax pattern

\section{Preparation of Wax Patterns}

Before making wax patterns, a thin layer of lubricant was applied onto the gypsum dies and the dies were allowed to dry. The sleeve was also lubricated with petroleum jelly.

\section{Inlay Type B Pattern Wax}

Wax was melted in an electric wax bath. The stone dies and the metal sleeve were lubricated and the sleeve was fitted on the stone die. Fluid wax was poured into the gap between the stone die and the metal sleeve and the molten wax were allowed to cool down to room temperature. After the wax had cooled down to room temperature, the margins were redefined. The wax patterns were carefully removed from the die (-Fig. 7) and invested immediately.

\section{Autopolymerized Pattern Resin}

The acrylic material was applied by wetting a fine brush with monomer and dipping it in the powder to produce a bead of acrylic material and thus applied layer by layer constantly maintaining the length and width of the pattern using the sleeve. The acrylic resin pattern was trimmed carefully using the hand piece to exact dimensions. The patterns were
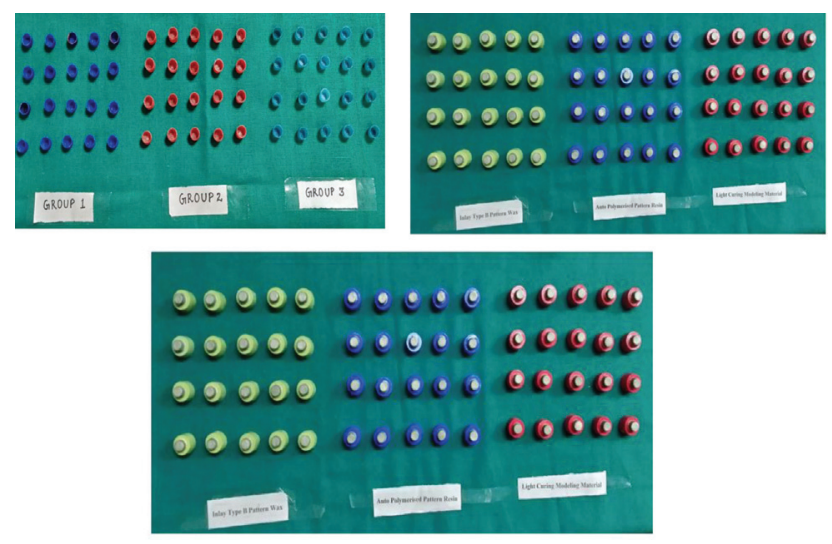

Fig 7 Patterns and castings group 1, 2, and 3. carefully removed with minimal distortion (-Fig. 7) and invested immediately.

\section{Light-Curing Modeling Material}

The adaptation of light-curing modeling materials onto the gypsum stone dies followed the application of a thin layer of separating medium on the dies. The sleeve was lubricated with petroleum jelly. The pattern material was layered and polymerized incrementally constantly maintaining the length and width of the pattern using the sleeve. After solidification of the Liwa wax die with counter sleeve was kept in light-curing chamber for 6 minutes curing cycle. After one curing cycle counter sleeve was removed and die with Liwa wax pattern was cured for 6 minutes of second curing cycle. The patterns were carefully removed with minimal distortion (-Fig. 7) and invested immediately.

All the patterns were carefully examined for void and marginal adaptation before investing and casting procedures were performed.

\section{Investing and Casting}

With standard protocol of lost wax technique, castings were done in induction casting machine

\section{Seating of the Castings on the Stone Dies}

The castings were retrieved and checked for nodules under the magnifying lens. They were removed using a round carbide bur, taking care only to grind away the nodule. These castings were then seated on the dies without any pressure (-Fig. 7). Visual assessment of marginal fit was made.

\section{Image Analysis}

The specimens were scanned using the stereo microscope (-Fig. 8).

The marginal discrepancies of the castings fabricated using inlay wax, autopolymerized pattern resin, and lightcuring modeling material were measured with the help of the Nikon imaging software (NIS) element. The finished copings were placed on the master die in a spring-loaded Vernier caliper. The marginal gap between external edge of
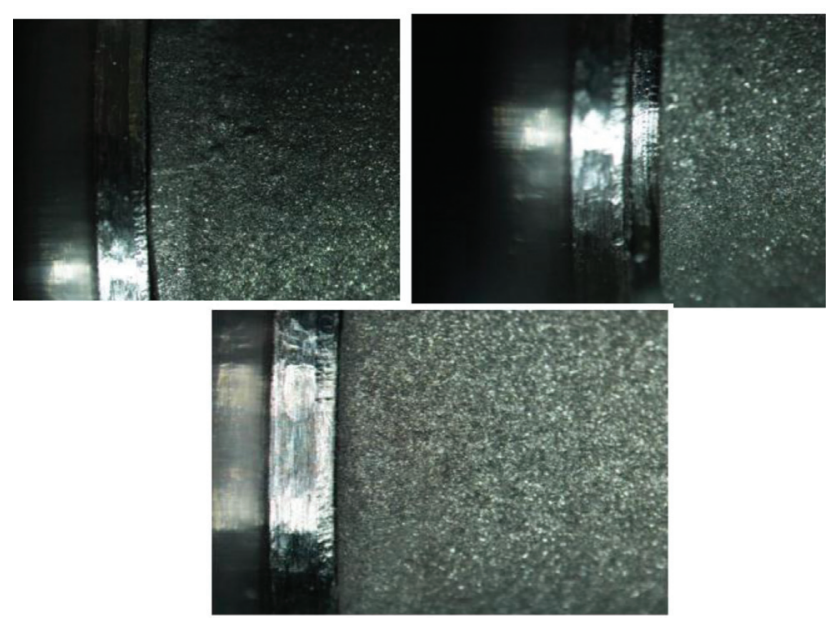

Fig 8 Stereo microscope images group 1, 2, and 3. 
structure and preparation limit was defined as the standard for marginal accuracy.

Three readings showing the marginal discrepancies for each die were taken and an average of three was taken as marginal discrepancy in microns. Data thus obtained was subjected to statistical analysis, tabulated, inference drawn, and evaluated for the accuracy of fit.

\section{Results}

During comparison of the results of the three materials, highest marginal discrepancies were seen in castings made by inlay type B pattern wax then autopolymerizing resin castings and least discrepancies were found in the castings made with light cure modelling material (-Table 1, - Fig. 9).

The mean gaps for the castings fabricated using inlay type B pattern wax, light cure modelling material, and for autopolymerized pattern resin were $65.136,44.705$, and 35.566 microns, respectively (-Table 2). For comparison, one-way analysis of variance (ANOVA) test and (post hoc tests) Bonferroni tests were performed (-Table 3 ). Significant difference $(p<0.05)$ in the marginal accuracy was observed between the castings fabricated using three types of pattern materials (-Table 4 ).

Table 1 Vertical marginal discrepancy recorded among all three groups (in microns)

\begin{tabular}{|c|c|c|c|}
\hline S. no. & $\begin{array}{l}\text { Group 1: } \\
\text { Inlay wax }\end{array}$ & $\begin{array}{l}\text { Group 2: } \\
\text { Autopolymerizing } \\
\text { resin }\end{array}$ & $\begin{array}{l}\text { Group 3: Light } \\
\text { cure modeling } \\
\text { material }\end{array}$ \\
\hline 1 & 62.50 & 46.66 & 35.16 \\
\hline 2 & 60.41 & 44.66 & 31.75 \\
\hline 3 & 65.91 & 44.33 & 37.91 \\
\hline 4 & 62.16 & 42.00 & 36.41 \\
\hline 5 & 65.50 & 43.60 & 36.33 \\
\hline 6 & 62.80 & 43.00 & 33.25 \\
\hline 7 & 68.60 & 46.16 & 41.91 \\
\hline 8 & 69.16 & 44.60 & 40.16 \\
\hline 9 & 69.33 & 45.16 & 40.08 \\
\hline 10 & 65.16 & 44.66 & 32.08 \\
\hline 11 & 65.16 & 47.16 & 30.58 \\
\hline 12 & 60.50 & 42.33 & 35.28 \\
\hline 13 & 69.50 & 44.16 & 33.33 \\
\hline 14 & 63.50 & 44.50 & 34.00 \\
\hline 15 & 64.50 & 42.63 & 41.16 \\
\hline 16 & 63.30 & 43.23 & 31.75 \\
\hline 17 & 68.50 & 45.50 & 33.50 \\
\hline 18 & 63.41 & 42.86 & 32.76 \\
\hline 19 & 65.33 & 43.16 & 35.08 \\
\hline 20. & 67.50 & 53.75 & 38.83 \\
\hline
\end{tabular}

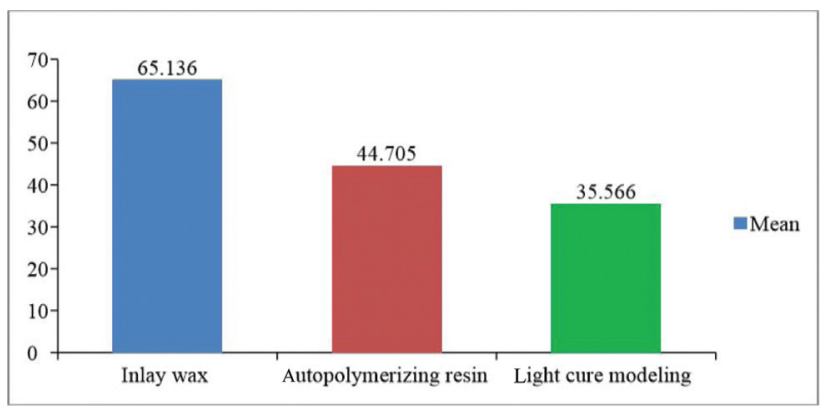

Fig 9 Mean comparison of marginal discrepancy of studied groups.

\section{Discussion}

To restore function and aesthetics of lost intraoral tooth structure, fixed partial dentures are given that do not hamper the oral or general health of patients. ${ }^{4}$ The main objective of any dental restoration is to create biologic, physical, and cosmetic requirements. ${ }^{5}$ For this fit of the margin is must for long-term success of a cast restoration. ${ }^{6}$ The fit and detail of a cast restoration will depend to a great extent on the accuracy and fine detail of the wax pattern. ${ }^{7}$ The casting procedure is complex, involving various stages, each of which may affect the dimensions, and therefore the accuracy of the final casting, which is going to withstand the rigors of the oral environment. The dimensional accuracy of the casting depends on the method of casting employed and various materials used in its fabrication. Basic fundamental principles of casting procedure have to be adhered to produce accurate castings. For better prognosis, constant monitoring of new materials and techniques has to be followed. Inlay waxes have properties of easy manipulation, better coefficient of thermal expansion with no residual burnout. However, with increase in temperature, there are thermal changes and with internal stresses there are chances of distortion. To avoid this distortion, pattern should be stored at low temperature and should be invested as soon as possible as removed from die. ${ }^{8}$

Alternatively, autopolymerizing resins are used for casting in place of inlay wax. Distortion is less as rotary instruments can be used with these materials. Resins have better dimensional stability and are easy to manipulate. Only disadvantage is polymerization shrinkage. Light-curing resins have low polymerization shrinkage, adequate

Table 2 Descriptive statistics (marginal discrepancy) of studied groups

\begin{tabular}{|l|l|l|l|l|}
\hline Group & $\boldsymbol{n}$ & Mean & SD & SE mean \\
\hline Inlay wax & 20 & 65.136 & 2.8748 & 0.6428 \\
\hline $\begin{array}{l}\text { Auto polymerizing } \\
\text { resin }\end{array}$ & 20 & 44.705 & 2.5595 & 0.5723 \\
\hline $\begin{array}{l}\text { Light cure modeling } \\
\text { material }\end{array}$ & 20 & 35.566 & 3.4185 & 0.7644 \\
\hline
\end{tabular}

Abbreviations: SD, standard deviation; SE, standard error. 
Comparative Evaluation of Three Pattern Materials on the Vertical Marginal Accuracy of Complete Cast

Table 3 Intergroup comparison (marginal discrepancy) of studied groups

\begin{tabular}{|c|c|c|c|c|c|}
\hline Marginal discrepancy & Sum of squares & df & Mean square & $F$ & $p$-Value \\
\hline Between groups & $9,169.396$ & 2 & 4584 & \multirow[t]{3}{*}{518.989} & \multirow[t]{3}{*}{$0.000^{*}$} \\
\hline Within groups & 503.533 & 57 & 8.834 & & \\
\hline Total & $9,672.929$ & 59 & & & \\
\hline
\end{tabular}

Abbreviations: ANOVA, analysis of variance; df, degree of freedom.

F-ANOVA value.

*Statistically significant.

Table 4 Multiple group comparison (marginal discrepancy) of studied groups

\begin{tabular}{|c|c|c|c|c|c|}
\hline \multirow[t]{2}{*}{ (I) Group } & \multirow[t]{2}{*}{ (J) Group } & \multirow[t]{2}{*}{ Mean difference (I-J) } & \multirow[t]{2}{*}{$p$-Value } & \multicolumn{2}{|c|}{ 95\% Confidence interval } \\
\hline & & & & Lower bound & Upper bound \\
\hline \multirow[t]{2}{*}{ Inlay wax } & Auto Autopolymerizing resin & 20.4310 & 0.9399 & $0.000^{*}$ & 18.113 \\
\hline & Light cure modeling material & 29.5710 & 0.9399 & $0.000^{*}$ & 27.253 \\
\hline \multirow[t]{2}{*}{ Autopolymerizing resin } & Inlay wax & -20.4310 & 0.9399 & $0.000^{*}$ & -22.749 \\
\hline & Light cure modeling material & 9.1400 & 0.9399 & $0.000^{*}$ & 6.822 \\
\hline \multirow{2}{*}{$\begin{array}{l}\text { Light cure modeling } \\
\text { material }\end{array}$} & Inlay wax & -29.5710 & 0.9399 & $0.000^{*}$ & -31.889 \\
\hline & Autopolymerizing resin & -9.1400 & 0.9399 & $0.000^{*}$ & -11.458 \\
\hline
\end{tabular}

"p" is level of significance; $p>0.05$ not significant; $p<0.05$ significant; $p<0.001$ highly significant.

*Statistically significant.

**Statistically nonsignificant.

dimensional stability, ease to manipulate, reduced chair side time, and no residue left after burnout. ${ }^{9}$

In the present study, marginal accuracy of cast crowns prepared with different pattern materials was compared. Under stereo microscope image analysis was done. The results were analyzed. Average of three readings in microns was noted.

The mean marginal discrepancy in casting with inlay type B pattern wax was 65.136 microns, autopolymerized pattern resin was 44.705 microns, and light-curing modelling material was 35.566 microns. One-way ANOVA test and Bonferroni test (post hoc tests) were used to compare marginal discrepancies. Significant difference $(p<0.05)$ in the marginal discrepancy was observed between the castings fabricated using three types of pattern materials.

The result showed that the highest marginal discrepancy in crowns were made with inlay type B pattern wax, then autopolymerizing resin and the least with light cure modelling material.

The mean average vertical marginal discrepancy for type B inlay wax was 65.136 microns and it ranged from 60.41 to 69.50 microns. The mean average vertical marginal discrepancy for autopolymerizing resin was 44.705 microns and it ranged from 42.00 to 53.75 microns.

The mean average vertical marginal discrepancy for light

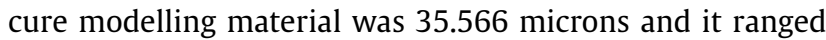
from 30.58 to 41.91 microns.

According to Rajagopal et al, light cured pattern resin was dimensionally stable material as compared with autopolymerized resin and inlay wax. ${ }^{10}$
Inlay waxes are easy to manipulate, good coefficient of thermal expansion with no residue left on dewaxing. However, on increasing temperature, there is thermal changes and inbuilt stresses may cause distortion. This step is important issue when investment is delayed or heating the wax pattern before the investment set. It should be stored in lowstorage temperature to minimize distortion and the patterns should be invested as soon as being removed from the preparation.

As discussed earlier, resins can be used in place of waxes because of ease of manipulation reduced distortion as the rotary instruments can be used with these materials. Only disadvantage is polymerization shrinkage.

Phillips and Biggs in their study showed that the distortion of wax pattern material is evident within 30 minutes of preparation of wax pattern so storage of wax pattern should be at low temperatures and should be invested as soon as removed from die. ${ }^{8}$

All the pattern materials have two major qualities that cause problem in usage: thermal changes and distortion. ${ }^{11}$ There are internal stresses due to change in temperature as the investment sets.

These stresses are released as the pattern is stored for longer period of time and the temperature at which it is stored. At higher temperatures, the flow increases and yield point of wax is lowered. ${ }^{12}$ Inlay waxes are not used in cases where high precision is required.

Studies conducted by Shillinburg have shown that autopolymerized resin pattern materials undergo a polymerization shrinkage of 1 to $7 \%$ on storage for 24 hours. To overcome 
the drawbacks of these materials, light cured pattern resins were introduced that have better fit and stability after polymerization. ${ }^{13}$ Light cure pattern materials required complete polymerization; otherwise there will be deformation leading to unfit casting.

\section{Limitation of the Present Study}

Within limitation of the current study, the marginal discrepancies of the cast crowns made from different pattern materials were not subjected to storage at different time intervals. Moreover, in this study, only vertical marginal discrepancies were observed as compared with the horizontal marginal discrepancies. This was not possible as in the study as sections of the specimens could not be done to see the internal gap. In future research, digital technology in form of CAD/CAM system can be used to fabricate patterns to ensure better consistency.

\section{Conclusion}

The present in vitro study was designed to evaluate and compare the effect of three different types of pattern materials, that is, inlay type B pattern wax, autopolymerizing resin, and light cure modelling material on the vertical marginal accuracy of complete cast crown.

The least amount of discrepancy was seen in light cure modeling resin. This is due to inherent strains in the inlay pattern wax that gets increased during pattern build up and casting resulting in an increased discrepancy in fit. As compared with pattern resin, light modeling material does not have any inherent strain thus producing better fit of castings.

So, it is recommended that light cure modeling material is best to make patterns for casting with lost wax technique.

Conflict of Interest

None declared.

\section{References}

1 Bhaskaran E, Azhagarasan NS, Miglani S, Ilango T, Krishna GP, Gajapathi B. Comparative evaluation of marginal and internal gap of Co-Cr copings fabricated from conventional wax pattern, 3D printed resin pattern and DMLS tech: an in vitro study. J Indian Prosthodont Soc 2013;13(03):189-195

2 Vinaya K, Rakshith H, Prasad D K, Manoj S, Sunil M, Naresh S. To evaluate \& compare retention of complete cast crown in natural teeth using different auxiliary retentive features with two different crown heights - an in vitro study. Int J Biomed Sci 2015;11 (02):99-106

3 Rossetti PHO, do Valle AL, de Carvalho RM, De Goes MF, Pegoraro LF. Correlation between margin fit and microleakage in complete crowns cemented with three luting agents. J Appl Oral Sci 2008;16 (01):64-69

4 Nawafleh NA, Mack F, Evans J, Mackay J, Hatamleh MM. Accuracy and reliability of methods to measure marginal adaptation of crowns and FDPs: a literature review. J Prosthodont 2013;22(05): 419-428

5 Assif D, Antopolski B, Helft M, Kaffe I. Comparison of methods of clinical evaluation of the marginal fit of complete cast gold crowns. J Prosthet Dent 1985;54(01):20-24

6 Bronson MR, Lindquist TJ, Dawson DV. Clinical acceptability of crown margins versus marginal gaps as determined by predoctoral students and prosthodontists. J Prosthodont 2005;14 (04):226-232

7 The Glossary of Prosthodontic Terms: Ninth Edition. J Prosthet Dent 2017;117(5S):e1-e105

8 Phillips RW, Biggs DH. Distortion of wax patterns as influenced by storage time, storage temperature, and temperature of wax manipulation. J Am Dent Assoc 1950;41(01):28-37

9 Sushma R, Farias A, Soni R. Vertical marginal discrepancies of metal castings obtained using different pattern materials: a scanning electron microscope study. J Int Clin Dent Res Organ 2014;6:98-102

10 Rajagopal P, Chitre V, Aras MA. A comparison of the accuracy of patterns processed from an inlay casting wax, an auto-polymerized resin and a light-cured resin pattern material. Indian J Dent Res 2012;23(02):152-156

11 Shamseddine L, Mortada R, Rifai K, Chidiac JJ. Marginal and internal fit of pressed ceramic crowns made from conventional and computer-aided design and computer-aided manufacturing wax patterns: an in vitro comparison. J Prosthet Dent 2016;116 (02):242-248

12 Craig RG, Eick JD, Peyton FA. Strength properties of waxes at various temperatures and their practical application. J Dent Res 1967;46(01):300-305

13 Shillinburg HT. Fundamental of Fixed Prosthodontics, third edition. Delhi: Quintessence Publishing Co.; 2012;1:140 